\title{
PELATIHAN PEMANFAATAN PERANGKAT LUNAK (MICROSOFT OFFICE WORD, EXCEL, POWER POINT) DALAM KINERJA PENGOLAHAN DATA DI PEMERINTAHAN DESA BAGI KEPALA DESA SE-KECAMATAN BATANG ANGKOLA
}

\author{
Masdelima Azizah Sormin, Nur Sahara, Lisna Agustina \\ Pendidikan Matematika, FKIP Universitas Muhammadiyah Tapanuli Selatan \\ masdelimaazizah@yahoo.com
}

\begin{abstract}
IbM discusses the utilization of software in assisting the village head Performance Sei Batang Angkola. His goal was to provide the skills and ability in using the device and take advantage of information and communication technology priority needs, improving basic capabilities in solving problems that will be faced in life in the village environment, enhancing the knowledge of computer-based administrative system, improve the skills of operating computer devices to improve the documentation of the data. The next performance is measured through the ability to process and use the software in question. Respondents who used as many as ten people on the research of the village chief in the village Batang Angkola. This dedication was held in Balai Village Purba Nauli Batang Angkola. The method of implementation is done in the form of training. Public service was conducted for three months, in January-March 2016. Where the activities of the training were held for two days in a row. The results of the training software are that the head of the village is already a lot of information and motivation so that in general the village chief has been able to operate your laptop or computer. External training activities resulting from this software is a journal with ISSN and services from training activities undertaken then expected to provide information, knowledge and can help the village chief in typing the letters to complete the administration of the village.
\end{abstract}

Key words: Software, The Performance Of The Village Chief, A Batang Village Of Angkola.

\begin{abstract}
Abstrak
IbM ini membahas pemanfaatan perangkat lunak dalam membantu Kinerja Kepala Desa SeKecamatan Batang Angkola. Tujuannya untuk memberikan bekal keterampilan dan kemampuan dalam menggunakan dan memanfaatkan perangkat teknologi informasi dan komunikasi menjadi prioritas kebutuhan, meningkatkan kemampuan dasar dalam memecahkan masalah yang akan dihadapi dalam kehidupan di lingkungan desa, meningkatkan pengetahuan mengenai sistem administrasi berbasis komputer, meningkatkan keterampilan mengoperasikan perangkat komputer guna memperbaiki dokumentasi data desa. Selanjutnya pada kinerja diukur melalui kemampuan mengolah serta menggunakan perangkat lunak yang dimaksud. Responden yang digunakan pada penelitian sebanyak 10 orang Kepala desa yang ada di desa kecamatan Batang Angkola. Pengabdian ini dilaksanakan di Balai Desa Purba Nauli Kecamatan Batang Angkola. Metode pelaksanaan yang dilakukan ialah berupa pelatihan. Pengabdian masyarakat ini dilaksanakan selama 3 bulan, pada bulan Januari - Maret 2016. Dimana kegiatan pelatihannya dilaksanakan selama dua hari berturut-turut. Hasil pelatihan perangkat lunak ini yaitu bahwa Kepala Desa sudah banyak memperoleh informasi dan motivasi sehingga pada umumnya Kepala Desa telah mampu mengoperasikan laptop atau komputer. Luaran yang dihasilkan dari kegiatan pelatihan perangkat lunak ini ialah Jurnal yang ber ISSN dan Jasa dari kegiatan pelatihan yang dilakukan maka diharapkan dapat memberikan informasi, pengetahuan serta dapat membantu Kepala Desa dalam pengetikan surat-surat guna melengkapi administrasi Desa.
\end{abstract}

Kata kunci: Perangkat Lunak, Kinerja Kepala Desa, Desa Kecamatan Batang Angkola.

$78 \mid$ MARTABE : Jurnal Pengabdian Masyarakat 


\section{PENDAHULUAN}

Di dalam pemerintahan
khususnya di desa, yang mengatur
sepenuhnya oleh kepala desa
diharapkan mampu menjalankan
pemerintahan dengan performa yang
baik dalam memberikan pelayanan
terhadap masyarakat, sehingga apabila
Aparat Pemerintah pada tingkat Desa
menunjukkan kinerja yang bagus dalam
penyelenggaran pemerintahan, maka
akan berhubungan pada kinerja
pemerintah pada tingkat Kabupaten,
Provinsi, hingga Pusat (Paramitha,
2010). Usaha untuk mencapai
pemerintahan yang baik ini melahirkan
Peraturan yang mengatur tentang
pelaksanaan Pemerintahan di Desa.
Salah satunya adalah UU Nomor 6
Tahun 2014 tentang Desa, pada pasal 26
ayat 1 dan 2 menjelaskan bahwa tugas
utama Kepala Desa adalah untuk
memimpin penyelenggaraan
Pemerintahan Desa. Bila ini dapat
terlaksanianata terlaksana dengan baik, maka tugas dan kewajiban yang lainnya sudah dapat terlaksana dengan baik pula.

Pemerintah telah menjadikan Teknologi menjadi salah satu bekal kemampuan yang dapat dimanfaatkan oleh pendidikan dan masyarakat khususnya di desa. Perangkat teknologi informasi dan komunikasi merupakan salah satu faktor kunci untuk mengejar ketertinggalan SDM Indonesia dari bangsa-bangsa lain (Ardoni, 2006). Program-program pendidikan dan latihan secara formal maupun non formal yang memberikan bekal ketrampilan dan kemampuan dalam menggunakan dan memanfaatkan perangkat teknologi informasi dan komunikasi menjadi prioritas kebutuhan (Rizki, 2014). Jalur pendidikan formal berpotensi dan bernilai strategis untuk menyelenggarakan pendidikan dan latihan di bidang TIK yang idealnya dimulai sejak dini. Hal ini mengisyaratkan pentingnya bagi kita semua disediakan pengalaman dalam memanfaatkan sarana teknologi informasi dan komunikasi khususnya komputer yang bermanfaat sebagai bekal kemampuan dasar dan potensi untuk belajar sepanjang hayat dan memecahkan masalah yang akan dihadapi dalam kehidupan di lingkungan desa kelak.

Perangkat lunak adalah seluruh perintah yang digunakan untuk memproses informasi. Perangkat lunak dapat berupa program atau prosedur. Perangkat Lunak (software) data elektronik yang disimpan sedemikian rupa oleh komputer itu sendiri, data yang disimpan ini dapat berupa program atauinstruksi yang akan dijalankan oleh perintah, maupun catatan-catatan yang diperlukan oleh komputer untuk menjalankan perintah yang dijalankannya. Untuk mencapai keinginannya tersebut dirancanglah suatu susunan logika, logika yang disusun ini diolah melalui perangkat lunak, yang disebut juga dengan program beserta data-data yang diolahnya.Pengeloahan pada software ini melibatkan beberapa hal, diantaranya adalah sistem operasi, program, dan data. Software ini mengatur sedemikian rupa sehingga logika yang ada dapat dimengerti oleh mesin komputer.

Perangkat lunak berupa microsoft office word, excel dan power point yang dapat dipergunakan bagi pembuatan surat-surat dalam pemberkasan administrasi di desa. Dimana dapat didiskusikan secara bebas oleh seluruh orang di muka bumi ini tanpa dikenakan biaya sepeserpun.Oleh karena itu dengan memanfaatkan perangkat lunak (microsoft office word, excel dan power point) ini diharapkan setiap orang dapat membuat laporan 
Rislisa, dkk. Seleksi Karyawan Pada Posisi Assistant Superintendent...

secara mandiri dan dapat menjadi pilot projectbagi tugas diskusi dalam setiap hasil rapat (Rahayu, 2011). Dan perangkat lunak (Microsoft office word,excel dan power point) juga dapat membantu kinerja dalam penulisan surat atau mempermudah administrasi desa.

\section{Permasalahan Mitra}

Perkembangan teknologi terus berkembang namun di desa kecamatan Batang Angkola masih tertinggal dalam hal teknologi khususnya dalam penggunaan komputer. Selain itu tempat kawasan desa jauh dari perkotaan yang masih banyak kekurangan. Terutama untuk kawasan yang di desa kecamatan batang angkola.

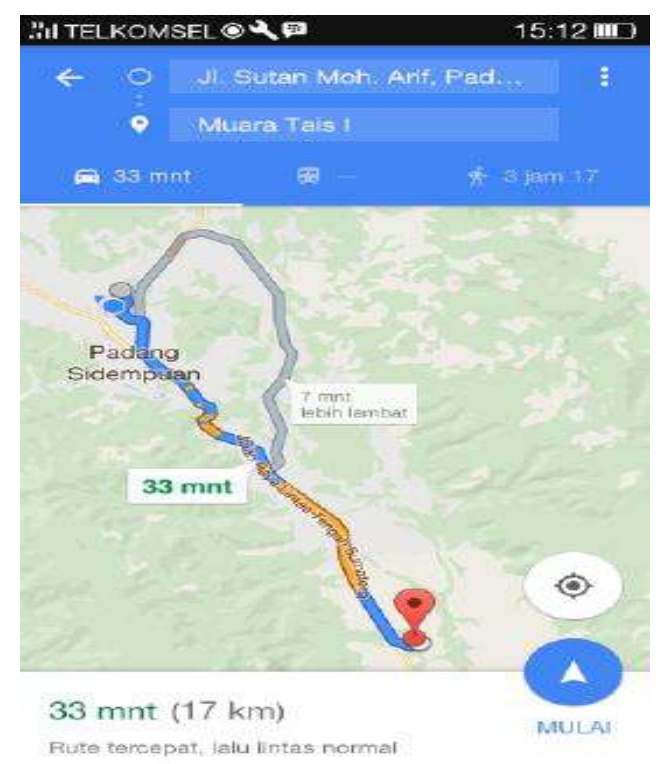

Gambar 1: Peta Desa Kecamatan Batang Angkola

Beberapa masalah yang dihadapi kepala desa di kecamatan Batang Angkola terkait dengan kurang memanfaatkan perangkat lunak yang ada dalam program Komputer. Menurut Agustina dkk (2017) Strategi yang tepat diharapkan mampu menumbuhkan kreativitas penggunaan, strategi penulisan surat yang ada di desa lebih dominan mengguanakan tulisan tangan sehingga memperlambat kinerja kepala desa.

\section{METODE PELAKSANAAN}

Untuk memamfaatkan perangkat lunak (Microsoft word, excel dan power point) bagi kepala desa khususnya yang ada di Kecamatan Batang Angkola maka perlu di adakannya pelatihan yang berkaitan dengan penggunaan perangkat lunak yang dimaksud guna untuk mempermudah kinerja kepala desa dalam administrasi surat. Namun demikian, para Kepala Desa belum sepenuhnya menggunakan perangkat tersebut dengan baik. Karena mereka pada umumnya masih memanfaatkan fasilitas yang ada yaitu masih secara manual. Salah satu upaya yang dilakukan untuk memecahkan permasalahan tersebut yaitu dengan melaksanakan kegiatan Pelatihan Pemanfaatan Perangkat Lunak (Microsoft word, excel dan power point) di desa Kecamatan Batang Angkola.

Pelatihan ini dilaksanakan agar kepala desa-kepala desa mampu menggunakan perangkat lunak komputer yang sudah ada dan berkembang pesat sehingga tujuan yang diharapkan dapat tercapai, sehingga ketertinggalan teknologi di desa berkurang dan setiap kepala desa lebih mudah dan praktis dalam kinerja administrasi yang ada di desa masingmasing.

\section{HASIL DAN PEMBAHASAN}

Kegiatan pelatihan ini terlaksana sesuai dengan yang diharapkan. Hal ini dapat dilihat dari hari ke-1 dan ke-2. Adapun hasil yang diperoleh dapat 
ditunjukkan berdasarkan pelaksanaan yang dilakukan dengan pembahasan sebagai berikut:

Hari ke-1

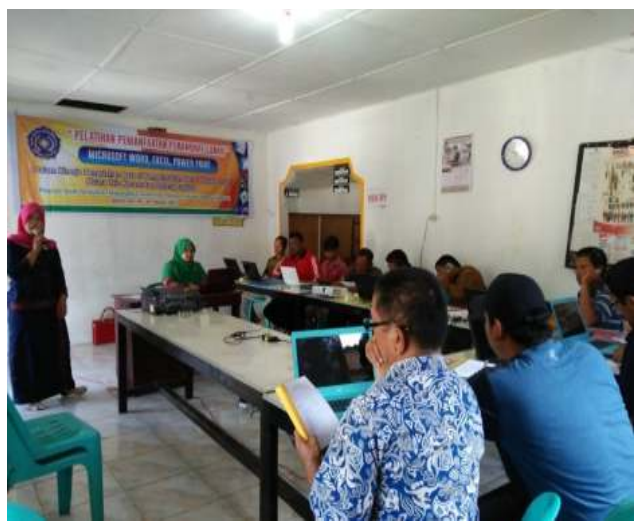

Gambar 2: Kegiatan Pelatihan

Kegiatan hari pertama yaitu tim pengabdian masyarakat memotivasi kepala desa terkait betapa pentingnya teknologi khususnya computer atau laptop. Guna untuk memperlancar kinerja administrasi yang ada di Desa. Kegiatan ini dapat dikatakan terlaksana dengan baik hal ini didasari oleh antusias para peserta dalam mengikuti kegiatan. Ini dapat ditunjukkan berdasarkan banyaknya pertanyaan dari Para peserta. Berikut adalah beberapa pertanyaan yang diajukan oleh peserta kepada narasumber/pemateri: Bagaimana cara menghidupkan dan mematika komputer?, Apa-apa saja guna tombol yang ada di laptop?, Bagaimana cara mudah agar mahir dalam menggunakan teknologi?, Apa beda dan manfaat Microsoft Office (Microsoft word, excel dan power point)?, Pada saat kapan saja Microsoft Office (Microsoft word, excel dan power point) digunakan?

Berdasarkan pertanyaanpertanyaan yang diajukan para peserta pelatihan tersebut maka dapat dikatakan bahwa kegiatan berjalan dengan lancar sesuai yang diharapkan, menambah informasi dan pengetahuan bagi peserta ini didasari karena antusias peserta dalam mengikuti persentase dari awal sampai akhir kegiatan.

Hari ke-2

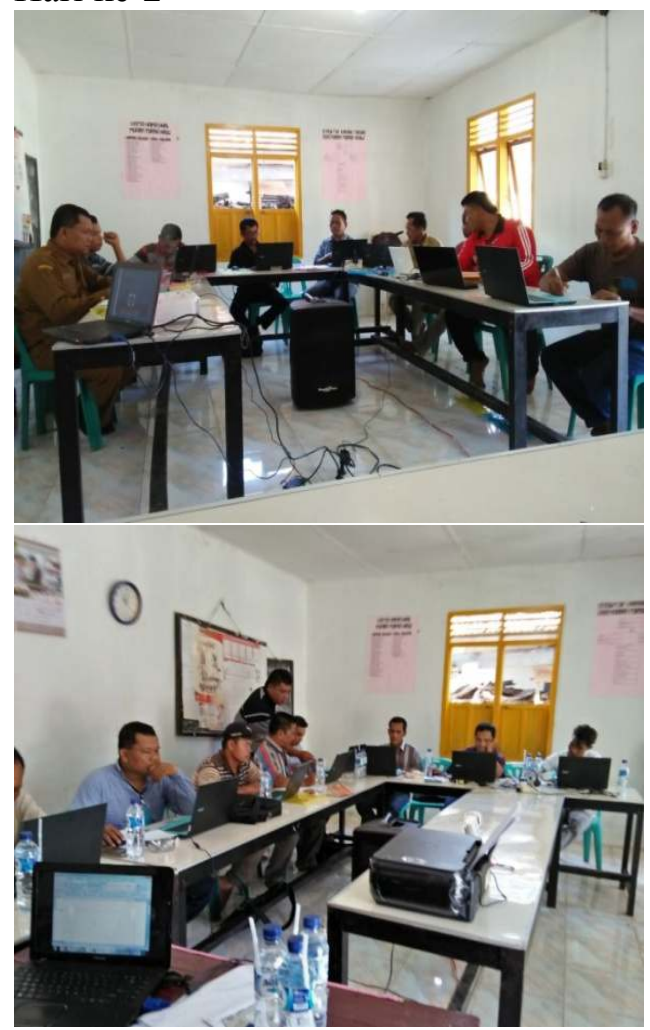

Gambar 3: Praktek Langsung

Kegiatan pelatihan pada hari ke dua ini merupakan puncak dari kegiatan pelatihan karena pada hari ke dua ini membahas tentang praktek langsung dengan laptong masing-masing. Berdasarkan hasil pengamatan dan hasil pelaksanaan maka kegiatan pelatihan ini memberikan hal-hal yang baru bagi para peserta pelatihan dan sekaligus memberikan manfaat yang besar untuk administrasi desa, dimana sebelumnya para peserta belum pernah diberikan seminar/pelatihan terkait teknologi Microsoft office. Kegiatan ini dapat dikatakan berhasil dan terlaksana hal ini juga di dasarkan pada antusias para peserta mengikuti kegiatan dan antusias dalam mengajukan pertanyaan. Berikut 
Rislisa, dkk. Seleksi Karyawan Pada Posisi Assistant Superintendent...

adalah pertanyaan-pertanyaan yang diajukan para peserta peserta: Bagaimana cara kita mencopy document yang dicatat ke document baru?, Bagaimana Cara meletakkan logo pada layar Microsoft word?, Bagaimana cara membuat cop Surat?, Bagaimana menyambungkan plasdisk ke laptop?, Bagaimana membuat rata kiri, rata kanan, rata tengah dan sama rata?, Apakah ada cara cepat dalam menguasai tombol-tombol yang ada di keyboard?, Bagaimana menyimpan berkas ke dalam file folder?, Bagaimana membuat tabel?, Bagaimana cara membuat tulisan besar, menebalkan huruf?, Bagaimana cara memprint?

Berdasarkan pengamatan terhadap pertanyaan-pertanyaan yang diajukan oleh para peserta terlihat bahwa para peserta sudah memiliki gambaran terkait kinerja yang akan dibuat. Peserta pelatihan juga antusian mengikuti jalannya kegiatan pelatihan ini dapat dilihat dari banyaknya peserta yang merespon/bertanya terkait materi yang disajikan. Berdasarkan jenis pertanyaan yang diajukan maka dapat disimpulkan bahwa para peserta sudah banyak memiliki informasi terkait teknologi computer microsoft office sehingga kegiatan yang dilaksanakan dapat terlaksana sesuai yang diharapkan.

\section{SIMPULAN}

Berdasarkan hasil kegiatan pelatihan yang sudah dilakukan, maka diperoleh kesimpulan sebagai berikut: Diperoleh feedbac yang positif dari pihak Pemerintah Desa, Kepala Desa Se-Kecamatan Batang Angkola selama mengikuti kegiatan pelatihan, Bertambahnya informasi, pengetahuan, dan pemahaman Kepala Desa SeKecamatan Batang Angkola terkait dalam pemanfaatan Perangkat Lunak,
Kepala Desa Se-Kecamatan Batang Angkola sudah mampu membuat surat keterangan sendiri, dan Tingginya motivasi yang dimiliki oleh Kepala Desa Se-Kecamatan Batang Angkola dalam melaksanakan kegiatan pelatihan.

\section{UCAPAN TERIMA KASIH}

Pengabdian ini terlaksana dengan bantuan berbagai pihak, terima kasih kepada pihak yang sudah membantu. LPPM dan Universitas Muhammadiyah Tapanuli Selatan (UMTS) kontrak No. Kept 13/07/11.3.AU/C/2017.

\section{DAFTAR PUSTAKA}

Agustina Lubis, Fitri. Jalilah Azizah Lubis. Mutiara Lubis. 2017 "PEPRADASE" Pelatihan Praktikum Biologi Dengan Alat Dan Bahan Sederhana. MARTABE : Jurnal Pengabdian Masyarakat Vol 1 No 1.

Ardoni. 2006. Teknologi Informasi. Jurnal Studi Perpustakaan dan Informasi Vol 1 No 2.

Paramitha, M.L. dkk. 2010. Kinerja Aparat Pemerintahan Desa Dalam Rangka Otonomi Desa). Jurnal Administrasi Publik (JAP), Vol 1 No. 4.

Rahayu, T.N. Hariyanto. 2011. IbM Sistem Administrasi Desa Berbasis Komputer Prodi Ilmu Komunikasi FISIP Univet Bantara Sukoharjo.

Rizki, Muhammad. 2014. Hubungan Pendidikan Kepala Desa Dengan Kinerja Kepala Desa di Desa Pepara Kec. Tanah Paser. e-Journal Administrasi Negara, Vol 2 No 4. 